\title{
A ESCRITA DA FRASE NA ALFABETIZAÇÃO: O PAPEL DA CONSCIÊNCIA SINTÁTICA
}

\author{
Ana Paula Rigatti Scherer ${ }^{1}$ \\ Vera Wannmacher Pereira ${ }^{2}$
}

\section{RESUMO}

O presente artigo trata da importância da consciência sintática na escrita de frases durante a alfabetização. Foram investigados alunos do $1^{\circ}$ ano de três escolas diferentes: Grupo A, alunos inseridos no METRAMAR (TREVISAN, 2007); Grupo B, alunos que participaram do PECOS e Grupo C, alunos que não participaram do método ou programa. Foram realizados pré e pós-teste de consciência sintática e escrita de frases. Os resultados revelaram que os Grupos A e B apresentaram melhor pontuação na consciência sintática, porém a escrita do Grupo A apresentou melhor desempenho. Concluiu-se que é necessário o ensino sistemático de leitura e escrita de frases na alfabetização.

Palavras-chave: Escrita. Frases. Consciência sintática. Alfabetização.

\section{INTRODUÇÃO}

São notáveis os problemas enfrentados na educação que dizem respeito ao ensino da leitura e da escrita. Altos índices de reprovação, baixas notas no IDEB e grande número de alunos que concluem o ensino fundamental sem escrever e ler um texto fluentemente.

Há alguns anos, estudiosos da Fonoaudiologia e da Linguística preocupam-se em solucionar questões ligadas à alfabetização, à escrita e à leitura, propriamente ditas. As pesquisas realizadas apontam para os estudos na área da consciência fonológica, assumindo que a metalinguística é fundamental para aprender a escrita e a leitura de uma língua. 
Dessa forma, muitas pesquisas comprovam que há estreita relação entre a consciência fonológica e a aquisição da escrita (CONTENT, 1984; MORAIS et al. 1986; MORAIS; ALEGRIA; CONTENT, 1987; CARRAHER, 1986; MENEZES, 1999; COSTA, 2002; FREITAS, 2004; RIGATTI-SCHERER, 2008), já que para escrever é necessário converter fonemas em grafemas, e para ler, converter grafemas em fonemas.

A consciência fonológica faz parte da consciência metalingüística e é uma habilidade caracterizada pela representação consciente das propriedades fonológicas e das unidades constituintes da fala (SCLIAR-CABRAL, 1995).

Gough, Larson e Yopp (1995) referem que a consciência fonológica compreende uma constelação de habilidades cujos componentes possuem diferentes propriedades e desenvolvem-se em diferentes tempos. Sendo assim, não há como conceber a consciência fonológica de forma unitária, mas por diferentes níveis linguísticos: sílabas (bo-la), unidades intra-silábicas (rimas: bola - mola, aliterações: figo - fila) e fonemas (b-o-l-a).

Assim, para o conhecimento da leitura e da escrita no nível da palavra, utilizar a consciência fonológica torna-se imprescindível. No entanto, ao nível da frase, percebe-se que ela não é suficiente e é necessário recorrer a um nível metalinguístico superior: o da consciência sintática. Segundo Gombert (2003), a consciência sintática é a habilidade metalinguística de refletir sobre a estrutura sintática da linguagem oral.

Segundo Demont e Gombert (1996), a consciência sintática pode favorecer a aprendizagem da leitura, e vice-versa, assim como a consciência fonológica favorece a aprendizagem da escrita. Segundo os autores, comportamentos epissintáticos da fase pré-escolar predispõem o sucesso da aprendizagem da leitura, e este passa a promover maior reflexão sintática.

Assim, o presente artigo pretende investigar qual é o papel da consciência sintática na escrita de frases de crianças em processo de alfabetização. Como as primeiras evidências de comportamento metassintático podem ser encontradas na criança por volta dos 6 anos, pois nessa idade ela demonstra corrigir frases agramaticais (GOMBERT, 2003), é possível que no $1^{\circ}$ ano do Ensino Fundamental o desenvolvimento da consciência sintática possa favorecer o desempenho da escrita de alunos alfabetizandos. 


\section{METODOLOGIA}

A realização deste estudo contou com alunos de três turmas de $1^{\circ}$ ano do Ensino Fundamental de escolas particulares e públicas da região metropolitana de Porto Alegre. A amostra foi assim distribuída:

Grupo A -5 alunos do $1^{\circ}$ ano de uma escola particular;

Grupo B -5 alunos do $1^{\circ}$ ano de uma escola pública municipal;

Grupo $\mathrm{C}-5$ alunos do $1^{\circ}$ ano de uma escola pública municipal.

Os alunos que compunham os grupos tinham idade entre 6 a 6 anos e 6 meses. Cada grupo foi selecionado de acordo com os resultados do instrumento CONFIAS (Moojen e cols., 2003). Inicialmente o grupo era composto de 10 crianças, sendo que foram então selecionadas as com pontuação média, isto é, foram excluídas crianças com pontuações no instrumento muito acima e muito abaixo da média de cada grupo.

Em cada grupo havia meninas e meninos, sendo que não foi possível em grupos de 5 alunos, obter-se igual número para cada gênero.

O Grupo A era caracterizado por ser formado de alunos que participam desde a Educação Infantil do Método Trevisan de Alfabetização Marista - METRAMAR (TREVISAN, 2007). Esse método tem como objetivo iniciar a leitura de sentenças antes mesmo que as crianças aprendam a decodificar o código alfabético. No método, as sentenças iniciam com desenhos e pequenas palavras e letras que já podem ser lidas, facilitando a leitura e já estabelecendo os constituintes da frase.

O Grupo B estava inserido em uma turma de 1ํao de uma escola municipal, a qual participou, durante 6 meses, de um Programa de Estimulação em Consciência Sintática - PECOS, desenvolvido pela autora. Essa turma de $1^{\circ}$ ano participou, durante 6 meses, de 2 encontros semanais de $40 \mathrm{~min}$, onde eram realizadas atividades orais sobre consciência sintática (CAPOVILLA; CAPOVILLA; SOARES, 2004) e estruturação de frases (RÉQUÉDAT, 1966). As solicitações das atividades eram realizadas com fantoches, tornando o trabalho mais interessante $e$ lúdico. Em apêndice, encontra-se um exemplo de encontro.

O Grupo $C$ estava inserido em uma turma de $1^{\circ}$ ano de outra escola municipal que não participou do PECOS, nem mesmo de um trabalho específico em consciência sintática ou leitura e escrita de frases. 
O grupo $\mathrm{B}$ e $\mathrm{C}$ eram compostos de alunos com nível socioeconômico baixo e, o Grupo A, composto por crianças de nível socioeconômico médio. No entanto, a única turma de $1^{\circ}$ ano que participava do METRAMAR era pertencente a esta escola e a este nível socioeconômico, não sendo possível obter-se três grupos com mesmo nível socioeconômico. Utilizou-se o CONFIAS para manter maior uniformização dos sujeitos.

Em ambos os grupos, os pais leram e assinaram o consentimento livre e esclarecido para que os testes fossem iniciados. Nos três grupos foi realizado um pré e um pós-teste. Em ambos os momentos os sujeitos responderam à Prova de Consciência Sintática (CAPOVILLA; CAPOVILLA; SOARES, 2004) e a uma coleta de escrita de frases.

A Prova de Consciência Sintática é composta de quatro subprovas: julgamento gramatical, correção gramatical, correção de frases agramaticais e assemânticas e categorização de palavras. Nesta pesquisa foram utilizadas somente as três primeiras.

$\mathrm{Na}$ coleta de escrita de frases, os sujeitos eram solicitados a construir oralmente uma frase, de acordo com a figura apresentada e, após, escrever essa mesma frase. No pré-teste foram apresentadas duas figuras: uma para treino (somente construir a frase) e outra para realizar também a escrita. No pós-teste os sujeitos eram apresentados a três figuras e deveriam escrever uma frase sobre cada uma delas.

O pré-teste foi realizado no início do ano letivo e o pós-teste após 6 meses. Durante os 6 meses de intervalo, a turma de $1^{\circ}$ ano na qual estava inserido o Grupo B participou do PECOS (Programa de Estimulação em Consciência Sintática). Os demais grupos não participaram desse programa.

\section{RESULTADOS E DISCUSSÃO}

A realização do pré e pós-teste resultou em dados sobre a consciência sintática e a escrita de frases dos três grupos investigados. 


\subsection{Sobre a consciência sintática}

A Tabela 1 apresenta os resultados da consciência sintática do Grupo A, grupo que estava inserido no método METRAMAR. Ela está organizada por sujeito e sua respectiva pontuação em cada tarefa no pré e pós-teste da prova de consciência sintática. A pontuação total de cada tarefa e de cada sujeito está em destaque.

\section{Tabela 1 - Resultados da Prova de Consciência Sintática do Grupo A}

\begin{tabular}{|c|c|c|c|c|c|c|c|c|}
\hline \multirow[t]{2}{*}{ Alunos } & \multicolumn{4}{|c|}{ Pré-teste } & \multicolumn{4}{|c|}{ Pós-teste } \\
\hline & $\begin{array}{l}\text { Julg. } \\
\text { (Max. } \\
20)\end{array}$ & $\begin{array}{c}\text { Correção } \\
\text { gram. } \\
\text { (Max.10) }\end{array}$ & $\begin{array}{c}\text { Correção } \\
\text { frases } \\
\text { agram. e } \\
\text { assem. } \\
\text { (Max. 9) }\end{array}$ & $T$ & $\begin{array}{c}\text { Julg. } \\
\text { (Max. 20) }\end{array}$ & $\begin{array}{c}\text { Correção } \\
\text { gram. } \\
\text { (Max.10) }\end{array}$ & $\begin{array}{l}\text { Correção } \\
\text { frases } \\
\text { agram. e } \\
\text { assem. } \\
\text { (Max. 9) }\end{array}$ & $T$ \\
\hline S 1 & 19 & 4 & 2 & 25 & 19 & 5 & 0 & 24 \\
\hline S 2 & 18 & 1 & 0 & 19 & 19 & 6 & 3 & 28 \\
\hline S 3 & 19 & 5 & 1 & 25 & 19 & 7 & 9 & 35 \\
\hline S 4 & 15 & 6 & 6 & 27 & 18 & 3 & 7 & 28 \\
\hline S 5 & 19 & 3 & 0 & 22 & 20 & 7 & 6 & 33 \\
\hline Total & 90 & 19 & 9 & 118 & 95 & 28 & 25 & 148 \\
\hline
\end{tabular}

Observando a tabela, verifica-se que houve aumento considerável nas tarefas CG (Correção Gramatical) e CGAA (Correção Gramatical de frases Agramaticais e Assemânticas) do pré para o pós-teste, indicando que houve melhora na manipulação dos constituintes da frase ao longo do ano letivo. Os alunos do Grupo A envolveram-se diariamente em tarefas sintáticas durante $01^{\circ}$ ano, em razão da metodologia em que estavam inseridos, neste caso o METRAMAR (TREVISAN, 2007), no qual os alunos desenvolvem atividades de leitura e escrita levando em conta a frase e seus constituintes.

No total geral, o Grupo A passou de 118 pontos do pré-teste, para 148 no pós-teste, um acréscimo de 30 pontos. Com esse resultado é possível concluir que 0 trabalho voltado à leitura e escrita de frases proporciona o aumento da consciência sintática dos alunos envolvidos. Vale lembrar que o Grupo A não participou de programa de estimulação em consciência sintática (que foi realizado de forma oral), 
mas estava inserido em uma metodologia de ensino que abrange leitura e escrita de frases.

A Tabela 2 apresenta os resultados da consciência sintática do Grupo B, grupo que participou do PECOS (Programa de Estimulação em Consciência Sintática).

\section{Tabela 2 - Resultados da Prova de Consciência Sintática do Grupo B}

\begin{tabular}{|c|c|c|c|c|c|c|c|c|}
\hline Alunos & & Pré- & ste & & & Pós-t & & \\
\hline & $\begin{array}{l}\text { Julg. } \\
\text { (Max. } \\
20)\end{array}$ & $\begin{array}{c}\text { Correção } \\
\text { gram. } \\
\text { (Max.10) }\end{array}$ & $\begin{array}{c}\text { Correção } \\
\text { frases gram. } \\
\text { e assem. } \\
\text { (Max. 9) }\end{array}$ & $T$ & $\begin{array}{c}\text { Julg. } \\
\text { (Max. 20) }\end{array}$ & $\begin{array}{c}\text { Correção } \\
\text { agram. } \\
\text { (Max.10) }\end{array}$ & $\begin{array}{c}\text { Correção } \\
\text { frases } \\
\text { Gram. } \\
\text { e assem. } \\
\text { (Max. 9) }\end{array}$ & $\bar{T}$ \\
\hline S1 & 15 & 4 & 5 & 24 & 19 & 9 & 5 & 33 \\
\hline S2 & 17 & 4 & 4 & 25 & 20 & 3 & 6 & 29 \\
\hline S3 & 18 & 4 & 6 & 28 & 17 & 4 & 6 & 27 \\
\hline S4 & 17 & 0 & 4 & 21 & 20 & 3 & 7 & 30 \\
\hline S5 & 15 & 2 & 2 & 19 & 19 & 7 & 6 & 32 \\
\hline Total & 82 & 14 & 21 & 117 & 95 & 26 & 30 & 151 \\
\hline
\end{tabular}

Observando a tabela, verifica-se que na tarefa 'julgamento' houve maior aumento de pontuação do pré para o pós-teste em comparação ao Grupo A. No préteste, a pontuação foi de 82 e no pós-teste foi de 95 . Percebe-se com isso que o Grupo B obteve maior aumento da pontuação desta tarefa do pré para o pós-teste, se comparado ao Grupo A, indicando que o PECOS pode ter favorecido o melhor julgamento desses sujeitos com relação às frases.

$\mathrm{Na}$ tarefa CG houve também maior aumento do pré (14 pontos) para o pósteste (26 pontos) no Grupo B se comparado ao Grupo A. Na tarefa CGAA o aumento da pontuação do Grupo $B$ do pré para o pós-teste não foi tão grande quanto ao do Grupo A, no entanto o desempenho do Grupo B foi melhor que o Grupo A, já que chegou a 30 pontos, comparado aos 25 pontos do Grupo A. No total geral, o Grupo B obteve no pré-teste uma pontuação de 117 e no pós-teste 151, resultando em 34 pontos de crescimento, maior que o do Grupo A, que foi de 30 pontos. 
Essa diferença pode estar justificada pelo fato de que o Grupo $B$ inseriu-se no PECOS durante 6 meses diferentemente do trabalho desenvolvido no Grupo A (METRAMAR). O PECOS desenvolveu diferentes habilidades nos sujeitos, proporcionando maior sensibilidade auditivo-verbal com relação às frases. Já o METRAMAR apresenta uma proposta de leitura e escrita, diferentemente do PECOS.

A Tabela 3 apresenta os resultados da consciência sintática do Grupo C, grupo que não se inseriu em nenhum método ou programa relacionado à consciência sintática ou à leitura e escrita de frases.

Tabela 3 - Resultados da Prova de Consciência Sintática do Grupo C

\begin{tabular}{|c|c|c|c|c|c|c|c|c|}
\hline \multirow[t]{2}{*}{ Alunos } & \multicolumn{4}{|c|}{ Pré-teste } & \multicolumn{4}{|c|}{ Pós-teste } \\
\hline & $\begin{array}{l}\text { Julg. } \\
\text { (Max. } \\
\text { 20) }\end{array}$ & $\begin{array}{l}\text { Correção } \\
\text { gram. } \\
\text { (Max.10) }\end{array}$ & $\begin{array}{c}\text { Correção } \\
\text { frases } \\
\text { agram. } \\
\text { e } \\
\text { assem. } \\
\text { (Max. 9) }\end{array}$ & $T$ & $\begin{array}{l}\text { Julg. } \\
\text { (Max. } \\
20 \text { ) }\end{array}$ & $\begin{array}{l}\text { Correção } \\
\text { agram. } \\
\text { (Max.10) }\end{array}$ & $\begin{array}{c}\text { Correção } \\
\text { frases } \\
\text { agram. } \\
\text { e } \\
\text { assem. } \\
\text { (Max. 9) }\end{array}$ & $\bar{T}$ \\
\hline S1 & 18 & 4 & 6 & 28 & 11 & 5 & 0 & 16 \\
\hline S2 & 17 & 5 & 0 & 22 & 20 & 2 & 2 & 24 \\
\hline S3 & 11 & 0 & 0 & 11 & 11 & 0 & 0 & 11 \\
\hline S4 & 16 & 0 & 0 & 16 & 19 & 6 & 6 & 31 \\
\hline S5 & 17 & 3 & 0 & 20 & 17 & 3 & 3 & 23 \\
\hline Total & 79 & 12 & 6 & 97 & 78 & 16 & 11 & 105 \\
\hline
\end{tabular}

O que chama a atenção nos resultados deste grupo é o pequeno ou nenhum aumento da pontuação do pré para o pós-teste em todas as tarefas da prova de consciência sintática. Na tarefa 'Julgamento' a pontuação total no pré-teste foi de 79 pontos, enquanto que no pós-teste a pontuação diminuiu para 78 pontos. Na tarefa CG a pontuação do pré-teste foi de 12 pontos e no pós-teste aumentou para 16 pontos. Na tarefa CGAA, em que houve um aumento mais considerável, a pontuação passou de 6 pontos no pré para 11 pontos no pós-teste.

Se for analisada a pontuação do total geral, vê-se que, de 97 pontos que 0 grupo obteve no pré-teste, houve um aumento de 8 pontos para o pós-teste, totalizando 105 pontos. 
Esses resultados do Grupo C podem ser explicados pela ausência do trabalho em consciência sintática ou até mesmo de um trabalho mais sistemático ao nível da frase. Os alunos deste grupo não participaram do PECOS (Programa de Estimulação em Consciência Sintática) desenvolvido pela autora, nem mesmo participaram do METRAMAR (Método Trevisan de Alfabetização Marista). Dessa forma, os alunos pouco desenvolveram suas habilidades metalinguísticas para lidar com as estruturas sintáticas, obtendo resultados na prova de consciência sintática bem abaixo dos grupos $A$ e $B$.

\subsection{Sobre a escrita das frases}

A coleta de escrita da frase ocorreu no pré e pós-teste, conforme figuras selecionadas e apresentadas aos sujeitos. No pré-teste, a maioria dos sujeitos, de ambos os grupos, apresentou hipótese de escrita pré-silábica (FERREIRO; TEBEROSKY, 1985), já que esta coleta realizou-se no início do ano letivo.

No entanto, o pós-teste revelou resultados muito interessantes quanto à escrita das frases.

No Grupo A, os sujeitos apresentaram escrita na hipótese alfabética e formação de frase adequada, respeitando a gramaticalidade, apresentando concordância verbal e nominal e delimitação entre os constituintes. A maioria dos sujeitos não apresentou hipo ou hipersegmentação. O Quadro 1 apresenta os resultados.

Quadro 1 - Resultados da escrita do Grupo A no pós-teste

\begin{tabular}{ll}
\hline Alunos & Pós-teste \\
\hline Sujeito 1 & Hipótese alfabética. \\
& $\begin{array}{l}\text { Formação de frase adequada, respeitando a } \\
\text { gramaticalidade. }\end{array}$ \\
& Hipótese alfabética. \\
& Formação de frase adequada, respeitando a \\
& gramaticalidade. \\
& Presença de hipossegmentação \\
\hline
\end{tabular}




\begin{tabular}{ll}
\hline Sujeito 3 & Hipótese alfabética. \\
& $\begin{array}{l}\text { Formação de frase adequada, respeitando a } \\
\text { gramaticalidade. }\end{array}$ \\
Sujeito 4 & Hipótese alfabética. \\
& Formação de frase adequada, respeitando a \\
& gramaticalidade. \\
& Presença de hipossegmentação no \\
& predicado \\
& Hipótese alfabética. \\
& Formação de frase adequada, respeitando a \\
Sujeito 5 & gramaticalidade. \\
\hline
\end{tabular}

A Figura 1 traz um exemplo de escrita de um sujeito do Grupo A. Percebe-se a delimitação dos constituintes e a formação da frase adequada.

Figura 1 - Escrita de um sujeito do Grupo A, no pós-teste.

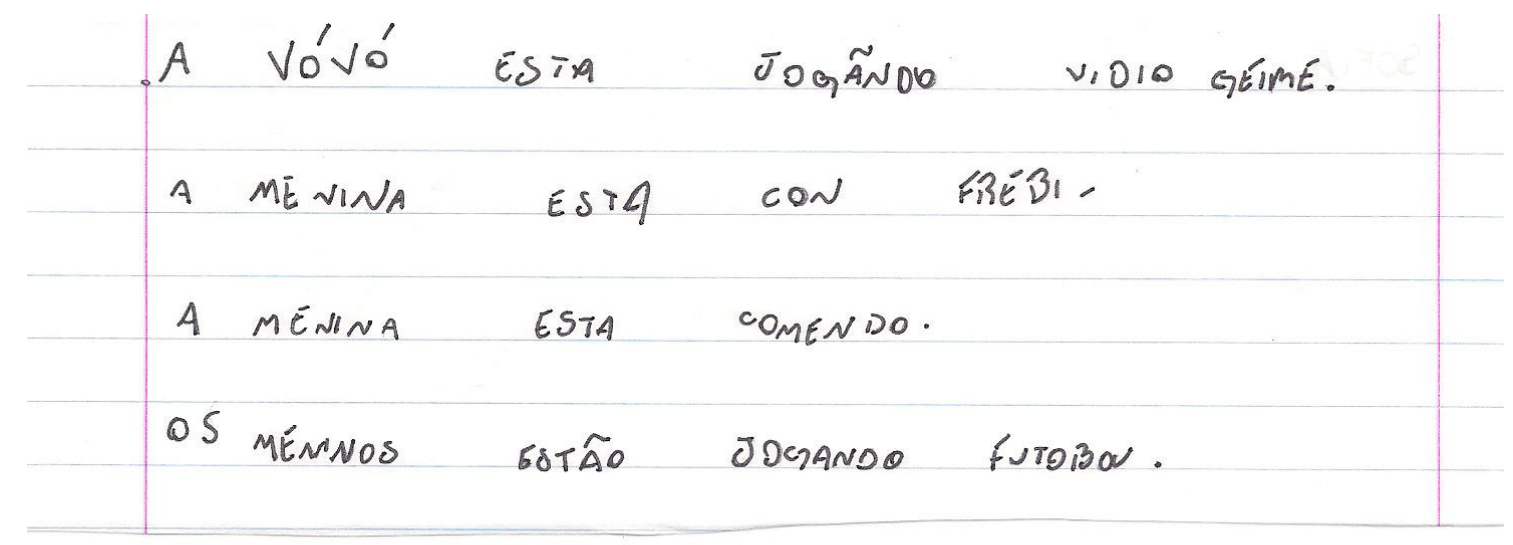

Essas características apresentadas pelos sujeitos do Grupo A podem ser justificadas pelo trabalho realizado em sala de aula com base no METRAMAR, método que enfatiza o uso de frases no ensino da leitura e da escrita mesmo antes de os alunos estarem lendo e escrevendo. No METRAMAR os alunos utilizam desenhos no lugar de palavras e com isso é visivelmente possível identificar essas fronteiras entre constituintes. Quando o aluno enfim dominar a escrita, terá mais condições de compreender o limite entre as palavras de uma frase. No Grupo A, 
portanto, houve uma forte contribuição do trabalho sintático do método utilizado na performance de escrita no nível da frase.

No Grupo B, os resultados já foram diferentes. A maioria dos sujeitos apresentou hipótese alfabética de escrita, um deles permanecia na hipótese présilábica e outro estava na hipótese silábica. Mesmo assim, observando até mesmo a escrita da frase do sujeito silábico, é notável a presença de hipo e hipersegmentação em praticamente todas as escritas.

\section{Quadro 2 - Resultados da escrita do Grupo B no pós-teste}

\begin{tabular}{|c|c|}
\hline Alunos & Pós-teste \\
\hline Sujeito 1 & $\begin{array}{l}\text { Hipótese alfabética. } \\
\text { Formação de frase adequada, respeitando a } \\
\text { gramaticalidade. } \\
\text { Presença de hipossegmentação em toda a } \\
\text { estrutura }\end{array}$ \\
\hline Sujeito 2 & $\begin{array}{l}\text { Hipótese silábica } \\
\text { Formação de frase adequada, respeitando a } \\
\text { gramaticalidade. } \\
\text { Presença de hipossegmentação em toda a } \\
\text { estrutura }\end{array}$ \\
\hline Sujeito 3 & $\begin{array}{l}\text { Hipótese pré-silábica } \\
\text { Utilizou letras sem valor sonoro }\end{array}$ \\
\hline Sujeito 4 & $\begin{array}{l}\text { Hipótese alfabética. } \\
\text { Formação de frase adequada, respeitando a } \\
\text { gramaticalidade. } \\
\text { Presença de hipossegmentação em toda a } \\
\text { estrutura }\end{array}$ \\
\hline Sujeito 5 & $\begin{array}{l}\text { Hipótese alfabética. } \\
\text { Formação de frase adequada, respeitando a } \\
\text { gramaticalidade. } \\
\text { Presença de hipo e hipersegmentação }\end{array}$ \\
\hline
\end{tabular}


A Figura 2 traz um exemplo de escrita do sujeito 1, revelando a falta de delimitação dos constituintes da frase. No entanto, a escolha dos termos foi adequada, mantendo a concordância verbal e nominal.

Figura 2 - Exemplo de escrita do sujeito 1 do Grupo B, no pós-teste.

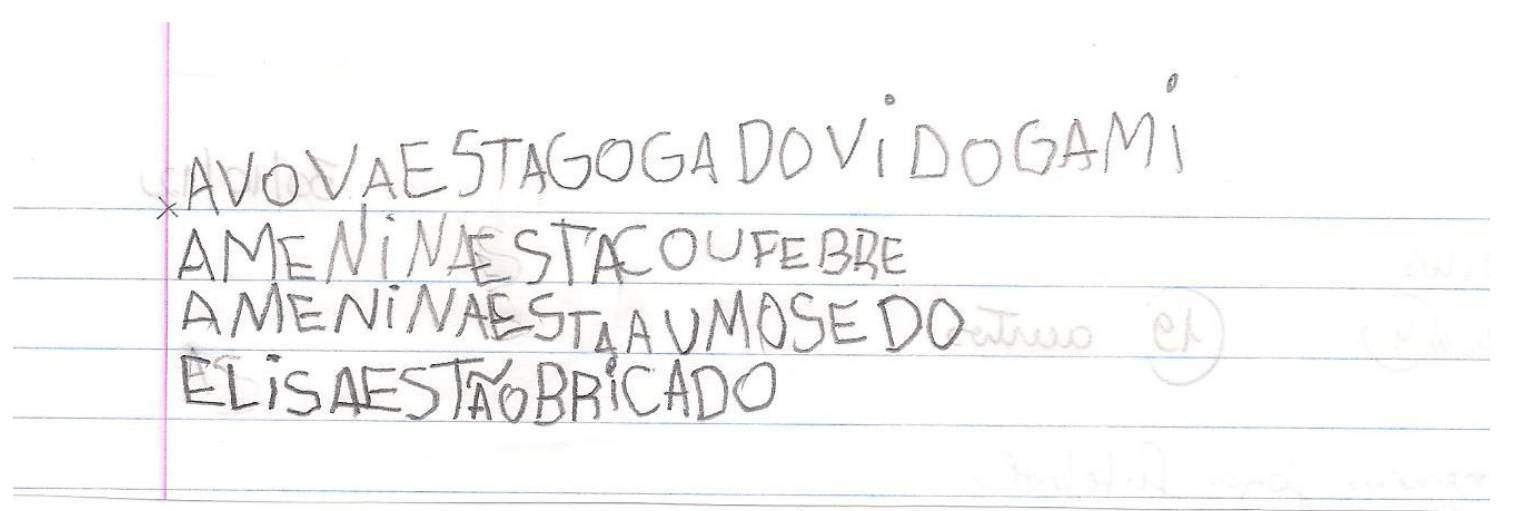

Os resultados da escrita do Grupo B apontam para um fato muito importante: o Programa de Estimulação em Consciência Sintática - PECOS não garantiu a delimitação dos constituintes da frase durante a escrita. Apesar de o PECOS aumentar consideravelmente a pontuação da consciência sintática dos sujeitos e facilitar a formação da frase, no sentido semântico e pragmático, ele não dá conta da delimitação dos componentes da frase. Como o PECOS funciona na forma auditivoverbal e os sujeitos não "visualizam" os componentes da frase, sejam eles desenhos ou palavras, o resultado é uma escrita com hipossegmentação, ou seja, sem espaços entre as palavras.

Os sujeitos do Grupo C, diferentemente dos demais, apresentaram, em sua maioria, hipóteses silábica e pré-silábica, ainda no pós-teste (Figura 5).

Quadro 3 - Resultados da escrita do Grupo C, no pós-teste.

\begin{tabular}{ll}
\hline \multicolumn{1}{c}{ Alunos } & \multicolumn{1}{c}{ Pós-teste } \\
\hline Sujeito 1 & Hipótese silábica. \\
& Utilizou uma letra para cada sílaba, fazendo \\
& hipos-segmentação em toda a estrutura \\
\hline
\end{tabular}




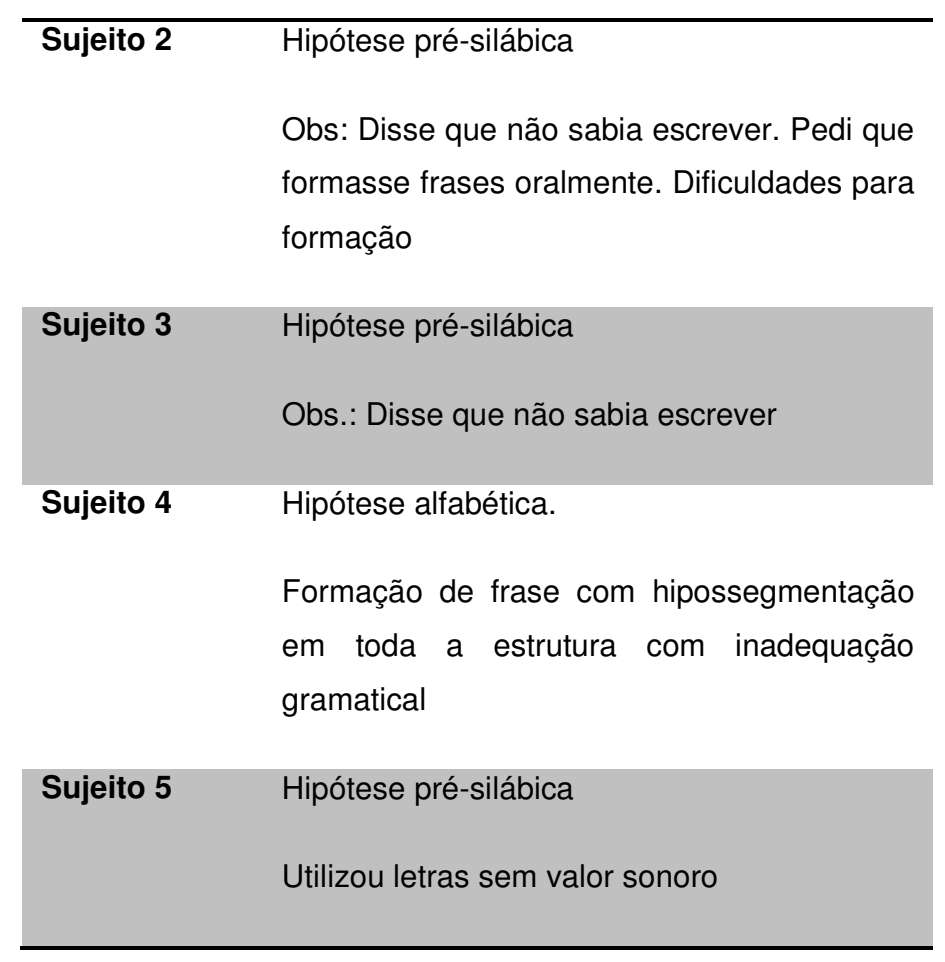

No quadro anterior, vê-se que somente um sujeito já estava com hipótese alfabética (sujeito 4). Esse sujeito escreveu a frase utilizando todos os componentes, porém com hiposegmentação em toda a estrutura, isto é, sem espaços entre as palavras. O sujeito 1 , com hipótese silábica, utilizou uma letra para cada sílaba ou palavra, sem haver delimitação entre os constituintes da frase, isto é, com hiposegmentação $O$ sujeito 2 foi solicitado a formar suas frases oralmente, já que disse não saber escrever. Resultado: frases incompletas, sem respeito à ordem gramatical utilizada, verbos abreviados (como por exemplo, 'tá' ao invés de 'está').

Os resultados do Grupo C podem ser justificados pelo fato de que os sujeitos desse grupo não participaram de nenhum programa ou trabalho específico com frases. Os sujeitos do Grupo A e B, pelo contrário, participaram de trabalho específico relacionado à sintaxe: ou desenvolvendo escrita e leitura de frases ou sendo estimulados à consciência sintática.

Percebe-se, portanto, a importância do trabalho realizado em sala de aula, no nível da frase, não bastando, somente, o trabalho no nível da palavra. É necessário haver ensino e trabalho sistemático da escrita no nível sintático. 


\title{
4 CONCLUSÃO
}

Os resultados encontrados confirmam a importância da consciência sintática para a leitura e escrita de frases. Foi observado que o Grupo B, que participou do PECOS - Programa de Estimulação em Consciência Sintática, sendo estimulado somente na forma auditivo-oral, obteve melhores resultados na pontuação da consciência sintática, porém não mostrou a qualidade esperada na escrita de frases. Já o Grupo A, que participou de uma metodologia com ênfase na escrita de frases, apesar de obter resultados na consciência sintática inferiores ao Grupo B, mostrou melhor qualidade na escrita de frases, realizando separações adequadas entre os constituintes. O Grupo C apresentou resultados inferiores tanto na consciência sintática quanto na escrita de frases.

Desta forma, os resultados podem indicar que somente a estimulação auditivooral da consciência sintática não é suficiente para que a escrita no nível sintático ocorra com a adequada delimitação de seus constituintes. É necessário um trabalho sistemático de escrita e leitura de frases para que os alunos escrevam utilizando a concordância adequada e estabeleçam limite entre os constituintes. É necessário haver sistematização do ensino da leitura e escrita de frases durante a alfabetização.

\section{NOTAS}

${ }^{1}$ Fonoaudióloga, doutora em Letras, professora do Curso de Fonoaudiologia da Faculdade Nossa Senhora de Fátima/Caxias-RS.

${ }^{2}$ Doutora em Letras, professora titular da Pontifícia Universidade Católica do Rio Grande do Sul (PUCRS).

\section{WRITING OF SENTENCES FOR LITERACY: THE ROLE OF SYNTACTIC AWARENESS}

\begin{abstract}
This article deals with the importance of syntactic awareness in the writing of sentences for literacy. We investigated the 1 st year students from three different
\end{abstract}


schools: Group A, students entered in METRAMAR (TREVISAN, 2007), Group B, students who participated in the PECOS and Group C students who have not participated in the program or method. Were performed pre-and post-test of syntactic awareness and writing sentences. The results revealed that groups $A$ and $B$ showed better scores on syntactic awareness, but the writing of Group A showed better performance. It was concluded that it is necessary the systematic teaching of reading and writing sentences in literacy.

Keywords: Writing. Phrases. Syntactic awareness. Literacy.

\section{REFERÊNCIAS}

CAPOVILLA, A.G.S.; CAPOVILLA, F.C.; SOARES, J.V.T. Consciência sintática no ensino fundamental: correlações com consciência fonológica, vocabulário, leitura e escrita. Psico-USF, v. 9, n. 1, p. 39-47, 2004.

CARRAHER, T.N. Explorações sobre o desenvolvimento da ortografia em português. Isto se aprende com o ciclo básico. Projeto Ipê. São Paulo: Secretaria de Estado da Educação - CENP, 1986. p. 109-117.

CONTENT, A. L' analyse phonétique explicite de la parole et l' acquisition de la lecture. L'année Psychologique, v. 84, 1984.

COSTA, A.C. Consciência fonológica: relação entre desenvolvimento e escrita. 2002. Dissertação (Mestrado em Lingüística Aplicada - Faculdade de letras)PUCRS, Porto Alegre, 2002.

DEMONT, E.; GOMBERT, J. E. Phonological awareness as a predictor of recoding skills and syntactic awareness as a predictor of comprehension skills.British. Journal of Educational Psychology, v. 66, p. 315-332, 1996.

FEEREIRO, E.; TEBEROSKY, A. A psicogênese da língua escrita. Porto Alegre: Artes Médicas, 1985.

FREITAS, G.M. Consciência fonológica e aquisição da escrita: um estudo longitudinal. 2004. Tese (Doutorado em Lingüística Aplicada - Faculdade de Letras)PUCRS, Porto Alegre, 2004.

GOMBERT, J. E. Atividades metalingüísticas e aprendizagem da leitura. In: MALUF, M. R. (Org.). Metalinguagem e aquisição da escrita: contribuições da pesquisa para a prática da alfabetização. São Paulo: Casa do Psicólogo, 2003. p. 19-64. 
GOUGH, P.; LARSON, K.; YOPP, H. A estrutura da consciência fonológica. In: CARDOSO-MARTINS, Cláudia. Consciência fonológica e alfabetização. Petrópolis: Vozes, 1995.

MENEZES, Gabriela. A consciência fonológica na relação fala-escrita em crianças com desvios fonológicos evolutivos. 1999. Dissertação (Mestrado em Lingüística Aplicada - Faculdade de Letras)-PUCRS, Porto Alegre, 1999.

MORAIS, J. ; ALEGRIA, J.; CONTENT, A. Segmental analysis and literacy. Chiers de Psychologie Cognitive, v. 7, n. 5, p. 415-437, 1987.

MORAIS, J. et al. Literacy training and speech segmentation. Cognition, v. 24, p. 4564, 1986.

RÉQUEDAT, F. Les exercices structuraux. France: Librairie Hachette, 1966.

RIGATTI-SCHERER, A.P. Consciência fonológica e explicitação do princípio alfabético: importância para o ensino da escrita. 2008. Tese (Doutorado em Letras Faculdade de Letras)-PUCRS, Porto Alegre, 2008.

SCLIAR-CABRAL, L. Da oralidade ao letramento: continuidades e descontinuidades. Letras de Hoje, Porto Alegre, v. 30, n. 2, p. 21-35, jun. 1995.

TREVISAN, A. Dissertação: Desenhando, Lendo e Escrevendo - DELES: uma proposta metodológica de alfabetizar. 2007. Dissertação (Programa de PósGraduação em Educação)-PUCRS, Porto Alegre, 2007. 


\section{APÊNDICE A \\ Programa de estimulação da Consciência Sintática (PECOS) \\ (Exemplo de encontro)}

Juiz Taxe: Crianças, vocês irão ouvir algumas frases. Quero que digam se estão corretas.

$\checkmark$ Eu comi bolo de chocolate.

$\checkmark$ João dançou na festa.

$\checkmark$ Eu morango comi de gelatina.

$\checkmark$ A menina passeou com seu pai.

$\checkmark$ Maria supermercado foi no.

$\checkmark$ A minha vó é divertida.

$\checkmark$ João gosta do professora.

$\checkmark$ Carol bonita é.

$\checkmark$ Adoro bolo de baunilha.

$\checkmark$ A papai dirige o carro.

Professora Sinta: Crianças, vocês irão ouvir algumas frases erradas. Gostaria que vocês corrigissem cada uma delas.

$\checkmark$ A vestido é verde.

$\checkmark$ Pedro comeu dois bananas.

$\checkmark$ Eu maçã gosto muito de.

$\checkmark$ Daniela bebeu todo a suco.

$\checkmark$ Domingo dia das mães foi.

Exercícios de repetição:

$\checkmark$ O dia está lindo!

$\checkmark$ Amanhã é quarta-feira.

$\checkmark$ Nós somos do primeiro ano.

Exercícios de substituição:

$\checkmark$ O dia está lindo.

$\checkmark$ O sol está lindo.

$\checkmark \_$está lindo.

$\checkmark$ O dia está lindo. 
$\checkmark$ O dia está

Exercícios de adição:

$\checkmark$ Amanhã é quarta-feira.

$\checkmark$ Amanhã é quarta-feira e vou na escola.

$\checkmark$ Amanhã é quarta-feira e

$\checkmark$ Amanhã é quarta-feira, vou na escola e depois para casa.

$\checkmark$ Amanhã é quarta-feira, e

Exercícios de redução:

$\checkmark$ Nós somos do primeiro ano da escola Inácio.

$\checkmark$ Nós somos do primeiro ano.

$\checkmark$ Nós somos do primeiro.

$\checkmark$ O menino acordou, tomou café e foi jogar bola.

Exercícios de transformação:

$\checkmark$ A menina bebeu leite.

$\checkmark$ Bebeu leite, a menina.

$\checkmark$ Maria foi na festa.

$\checkmark$

$\checkmark$ João caiu no chão.

$\checkmark$

Vovó Frasuda: Vamos ouvir a história: "Cachinhos dourados e os três ursos".

Agora, vou falar algumas frases sobre a história para que vocês digam se estão corretas.

$\checkmark$ Cachinhos prateados era uma menina.

$\checkmark$ Os três ursos deixaram pratos de macarrão em cima do mesa.

$\checkmark$ O ursos eram quatro.

$\checkmark$ A menina provaram o macarrão.

$\checkmark$ Cachinhos prateados nas deitou camas. 